\title{
Open access in medical publishing: trends and countertrends
}

I $\mathrm{n}$ the increasingly transient neighbourhood of medical journals publishing, the boldest new kid on the block is PLoS Medicine (http://medicine.plosjournals.org), a free-access general medical journal whose first issue appeared in October 2003. The enthusiastic editors and founders of the Public Library of Science, flush with a US\$9 million start-up grant from a private foundation, intend to "challenge the status quo" of medical publishing. The leading "conventional" journals like BMF, Lancet and the New England fournal of Medicine (and, yes, CMAf) are all over 70 years old, the PloS editors point out. Time for a shake-up, they say; time to "reinvent the medical journal."

Meanwhile, sadly, an intrepid pioneer in electronic medical publishing has installed a new entry system at its door. BM7's groundbreaking Web site now logs close to 2 million hits a week. For reasons vaguely cited as economic, BMF's publisher, the British Medical Association, is now imposing reader charges for nonsubscribers on all content except original scientific papers. ${ }^{2}$ This reduction in access is occurring as new open- and free-access journals are arriving, and at the moment that major libraries have agreed with Google to commit their collections to digitization and open access.

Since July 1999 the full text of $C M A 7$ has been available online without charge or restriction. We continue to experiment with online enhancements to our print content, and every issue of the journal published since 1911 will soon be available online. As models for medical journal publishing evolve in opposite directions, we are often asked, and ask ourselves, What have we learned? Will open access to $C M A 7$ continue?

We've learned that there are a lot of potential readers "out there": in 2005 we expect traffic to increase to close to 20 million hits. We also know that open access through the Internet has expanded our readership. Our most recent survey of online readers shows that only $31 \%$ of those who access eCMAZ identify themselves as physicians and more than half of our online readers access the site from outside Canada (see www.cmaj.ca/pdfs/eCMAJsurvey2004.pdf).

Promoters and detractors of free access agree that wider dissemination of scholarly and scientific content is a worthy goal. The disagreement concerns the economics of free-touser access. If grant money is not replenished, PLoS Medicine will be banking on author fees of US\$1500 per article; this cost will need to be built into funding for research. Other publishing models restrict access to paying sub- scribers and readers willing to pay per article. Clearly, either approach - placing cost recovery on the side of the author, or of the reader - creates barriers to the dissemination of research.

Money is important, even though the marginal additional costs of providing content free on the Web constitute a relatively small portion of the budget of a major print-based journal. In any case, even print subscribers want journal content available online for convenient searching and retrieval. The economic quandary that arises from open access hinges largely on the erosion of print subscription and advertising revenue that results when publications make their full contents available free online. The economic question is, How big are these losses, and are they balanced by noneconomic benefits?

At least for now it appears that most subscribers to journals like $B M 7$ and $C M A 7$ still like to have a hard copy of their journals and are willing to pay for it. Perhaps this will change when those born after the invention of the Web reach university and medical school. We'll have to wait a few more years to know. Subscriptions, although in modest decline with open access, are not yet in free-fall.

For $C M A \mathcal{A}$, the noneconomic benefits have included making the journal more attractive to authors, who want their work to be read and applied widely. We've seen our manuscript submissions increase dramatically, allowing $C M A 7$ 's peer reviewers and editors to raise the bar for quality and to select from a much wider range of content. We've seen satisfying increases in our Impact Factor, a measure of quality and an important magnet for authors whose careers and research-grant competitiveness are in part influenced by the prestige of the journals in which they publish. One day soon, new Internet payment models may enable electronic publications to apply pennies-per-view charges that defray editorial costs without creating a disincentive for readers. Or advertisers may be more willing to advertise on the Web. In the meantime, we intend to stick with open (and free) access without fees for readers or for authors. - $C M A 7$

\section{References}

1. Eisen MB, Brown PO, Varmus HE. PLoS Medicine - a medical journal for the Internet age. PLoS Med 1(1):e31. Available: http://medicine.plosjournals .org/perlserv/?request=get-static\&name=information (accessed 2004 Dec 13).

2. Access controls on bmj.com from 7 January BMJ policy. Available: http://bmj.bmjjournals.com/cgi/content/full/329/7478/DC1 (accessed 2004 Dec 20). 